\title{
Characteristics of TEC variations observed at Chofu for geomagnetic storms
}

\author{
A. Yamamoto ${ }^{1}$, Y. Ohta ${ }^{2}$, T. Okuzawa ${ }^{2}$, S. Taguchi² ${ }^{2}$ I. Tomizawa ${ }^{3}$, and T. Shibata ${ }^{2}$ \\ ${ }^{1}$ Japan Coast Guard Academy, Kure, Hiroshima 737-8512, Japan \\ ${ }^{2}$ Department of Information and Communication Engineering, University of Electro-Communications, Chofu, Tokyo 182-8585, Japan \\ ${ }^{3}$ Sugadaira Space Radio Observatory, University of Electro-Communications, Sugadaira, Nagano 386-2200, Japan
}

(Received January 14, 2000; Revised May 31, 2000; Accepted August 25, 2000)

\begin{abstract}
Since the middle of 1996 , we have made a routine observation of TEC using GPS in Chofu $\left(35.65^{\circ} \mathrm{N}, 139.54^{\circ} \mathrm{E}\right)$, Tokyo. We examine in this paper the relationship between the perturbation components of TEC and geomagnetic field variations during 11 storm events for 1997-1998 to clarify the mid-latitude characteristics of TEC variations at the time of magnetic storms. The perturbation components of TEC were derived every 20 seconds by subtracting quiet-time TEC values which are estimated as the average of both 3 days just before and after the storm period. The magnetic field data from Memambetsu Magnetic Observatory $\left(45.92^{\circ} \mathrm{N}, 144.20^{\circ} \mathrm{E}\right)$ are used for the identification of the storm-time variations. Our results show that (1) the amplitude level of the TEC variation tends to increase during the first $24 \mathrm{hr}$ of storm and then decrease below its usual-day level with recovery in one or two days later for the typical magnetic storm, and (2) during a negative-value phase of the TEC variation, which follows the initial positive hump structure, the perturbation amplitude of TEC shows a remarkable reduction in summer compared to in winter.
\end{abstract}

\section{Introduction}

Several investigators have shown that the observations of total electron content (TEC) by GPS can contribute to understanding of the characteristics of ionospheric perturbation (e.g., Jakowski, 1996; Lu et al., 1998; Saito et al., 1998). For example, Lu et al. (1998) have made global ionospheric maps of TEC observations from the worldwide network of GPS receivers to study the upper atmospheric response to a specific major magnetic storm on a simulation basis.

The storm-time relationship between the perturbation components of TEC and geomagnetic fields have been experimentally examined by several investigators in early days (e.g., Nakata, 1966; Mendillo et al., 1969; Titheridge and Buonsanto, 1988). Their results indicate that the TEC (of course non-GPS derived) increases during the first $24 \mathrm{hr}$ of a storm and then falls to below its quiet-day values with recovery in one or two days later for the typical storm. We examine in this paper the relationship between the perturbation components of TEC, which were derived from GPS dual frequency signals, and geomagnetic field variations for the 11 storms for 1997-1998 to clarify the mid-latitude characteristics of TEC variations at the time of magnetic storms.

\section{Data}

We obtained GPS-TEC data at Chofu $\left(35.65^{\circ} \mathrm{N}\right.$, $\left.139.54^{\circ} \mathrm{E}\right)$, Tokyo. The horizontal components $(\mathrm{H})$ of magnetic-field data from Memambetsu Magnetic Observatory $\left(45.92^{\circ} \mathrm{N}, 144.20^{\circ} \mathrm{E}\right)$, the Meteorological Agency, at which the storm features have been well defined, were used

Copy right (C) The Society of Geomagnetism and Earth, Planetary and Space Sciences (SGEPSS); The Seismological Society of Japan; The Volcanological Society of Japan; The Geodetic Society of Japan; The Japanese Society for Planetary Sciences. for comparison purpose. We deduced the TEC values with the cooperative use of the methods of both carrier phase and P-code group delay of GPS dual frequency signals. The Pcode delay was used for removing unknown integer cycle ambiguity of the carrier phase data. The vertically corrected data (VTEC) were obtained from the line of sight GPS observations using ionospheric shell model assumption (Mannucci et al., 1999). Namely, using a simplified obliquity factor, the VTEC is defined as

$$
\mathrm{VTEC}=\mathrm{TEC} \sqrt{1-\frac{\cos ^{2} E}{(1+h / r)^{2}}},
$$

where $r$ denotes mean earth radius, $E$ the elevation angle of the satellite, and $h$ the altitude of sub-ionospheric point which is assumed to be $400 \mathrm{~km}$ in this study. We excluded the TEC data for the elevation angles smaller than 30 degree so as to reduce possible errors in the estimation of VTEC.

Because we sometimes had trouble with our receiver by its excess heat, the dataset is not so large at present. Only 11 storm events were selected from 1997-1998 when we require that the data should be available during successive ten days or so. The selected 11 storm events are listed in Table 1 . The main phase depth of the decreasing $\mathrm{H}$ component is shown in Range column.

The perturbation components of TEC were derived every 20 seconds by subtracting the quiet-time values, which can be estimated as the average of both 3 days just before and after the storm period, for each satellite. The first three storm events, however, occurred successively, so that the average of Feb. 5-7 and 12-14 were used as the quiet-time values only for this case to reduce the effects of the adjacent storms. 


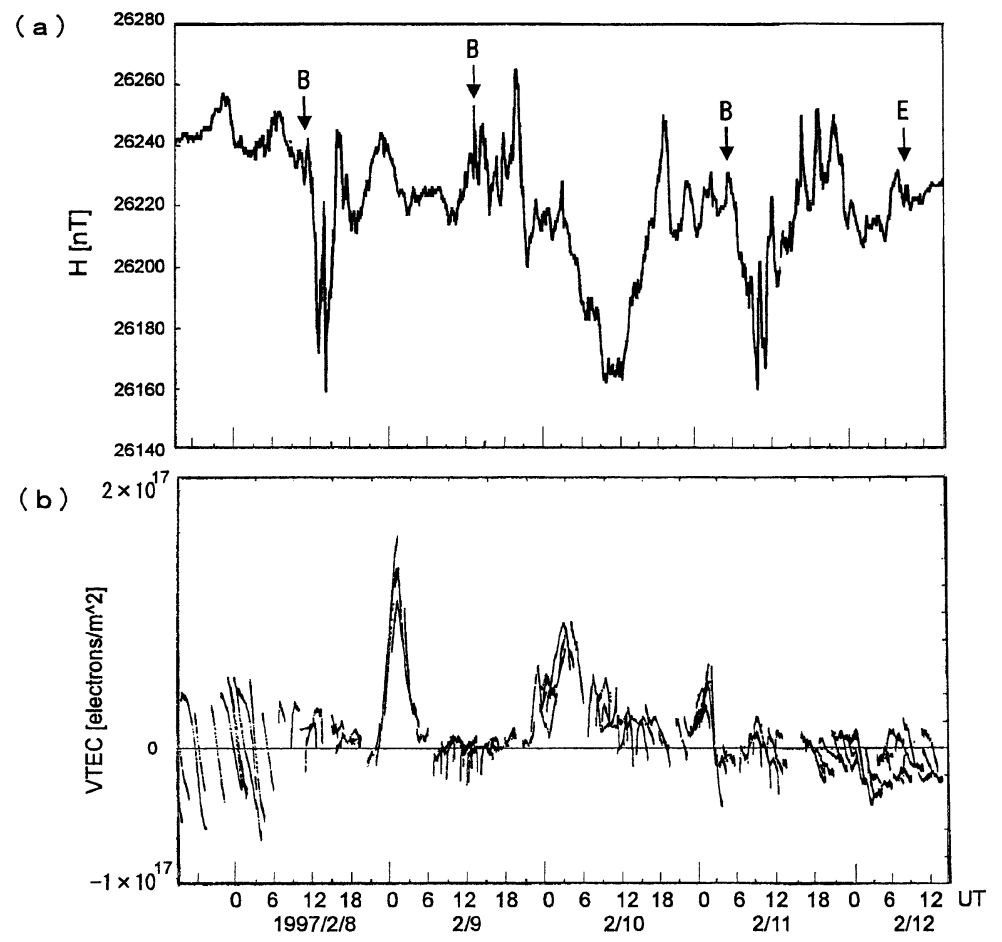

Fig. 1. Variations of (a) magnetic H-component and (b) the perturbation components of TEC associated with three successive storm events for Feb. 8-11, 1997.

Table 1. Selected magnetic storm events for 1997-1998 for this study.

\begin{tabular}{ccccc}
\hline $\begin{array}{c}\text { Beginning } \\
\text { (date, hour, min) } \\
\text { (UT) }\end{array}$ & $\begin{array}{c}\text { Ending } \\
\text { (date, hour) } \\
\text { (UT) }\end{array}$ & $\begin{array}{c}\text { SC } \\
(\mathrm{nT})\end{array}$ & $\begin{array}{c}\mathrm{K} \\
\text { Index }\end{array}$ & $\begin{array}{c}\text { Range } \\
(\mathrm{nT})\end{array}$ \\
\hline $97020809: 54$ & N/A & N/A & 5 & 88 \\
$97020913: 22$ & N/A & +24 & N/A & 104 \\
$97021104: 58$ & 97021210 & +6 & 5 & 93 \\
$97022718: 10$ & 97022823 & +7 & 6 & 130 \\
$97041613: 19$ & 97041815 & +13 & 5 & 101 \\
$97050112: 42$ & 97050210 & +18 & 5 & 95 \\
$97051501: 59$ & 97051600 & +17 & 7 & 172 \\
$97110622: 48$ & 97110800 & +9 & 5 & 151 \\
$97112209: 49$ & 97122400 & +30 & 6 & 180 \\
$98010614: 16$ & 97010719 & +26 & 5 & 116 \\
$98021713: 12$ & 98021900 & N/A & 5 & 89 \\
\hline
\end{tabular}

\section{Results}

The upper panel (a) of Fig. 1 shows the variation of $\mathrm{H}$-field for three successive magnetic storms. Each storm began at 09:54 on Feb. 8, at 13:22 on Feb. 9, and began at 04:58 on Feb. 11. Around 10:00 on Feb. 12 the storm activity ended. Symbols B and E in the figure indicate the beginning and ending of the storms, respectively. The perturbation component of GPS-TEC from all observable satellites during the same period is shown in the lower panel (b) of Fig. 1. We determined $400 \mathrm{~km}$ as the altitude of the sub-ionospheric point of GPS slant range, and limited analyses to the GPS elevation angles greater than 30 degree. Therefore, each GPS satellite spans the area of $1500 \mathrm{~km}$ in diameter at 400 $\mathrm{km}$ altitude for a flight over Chofu. This area is wide enough to allow for the simultaneous crossing of radio ray paths from other different GPS satellites. For this reason, the GPS-TEC in this figure have more than one values at the same time.

The magnetic field was sharply depressed with approximately $80 \mathrm{nT}$ in the night of Feb. 8. Accompanying with this small-scale magnetic disturbance, the amplitude level of TEC strongly increased with about 10 TECU $\left(1\right.$ TECU $=10^{16}$ electrons $/ \mathrm{m}^{2}$ ) in the next morning of Feb. 9. This amplitude of the perturbed TEC is similar to the one obtained by earlier investigators (e.g., Matuura, 1972). The TEC also grew larger on Feb. 10 and 11. This would be caused by the more severe storm of Feb. 10. The TEC variation affected by both the second and the third storms did not show so large amplitude as the first one. No clear response of the TEC to the third storm was identified, presumably because it was hidden behind the effect of the preceding (second) storm.

The conclusions from Fig. 1 are below. (1) The amplitude level of the TEC variations tends to increase during the first $24 \mathrm{hr}$, and then return to the usual-day level in a few days after the beginning of the storm, and (2) the TEC variation takes lower peak values for a typical magnetic storm such as the second one, than a small-scale storm such as the first storm event.

Figures 2 and 3 illustrate other examples showing the storm effect. As is seen in Fig. 2(a), a severe storm occurred for May $15-16,1997$ with the main phase decreasing in the evening of May 15. The storm affected the upper atmosphere in such a 
(a)

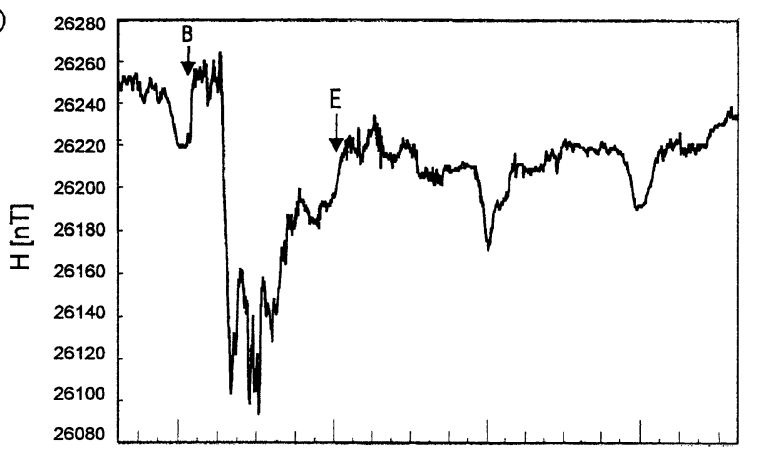

(b)

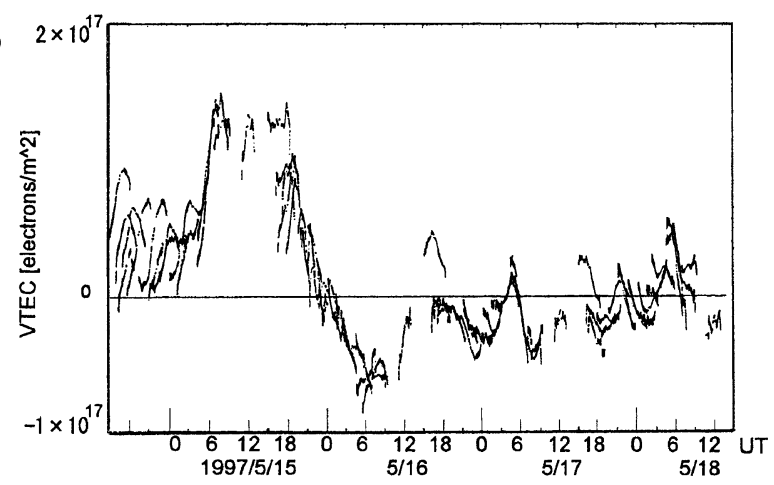

Fig. 2. Variations of (a) magnetic H-component and (b) the perturbation components of TEC associated with magnetic storm of May 15, 1997.

(a)

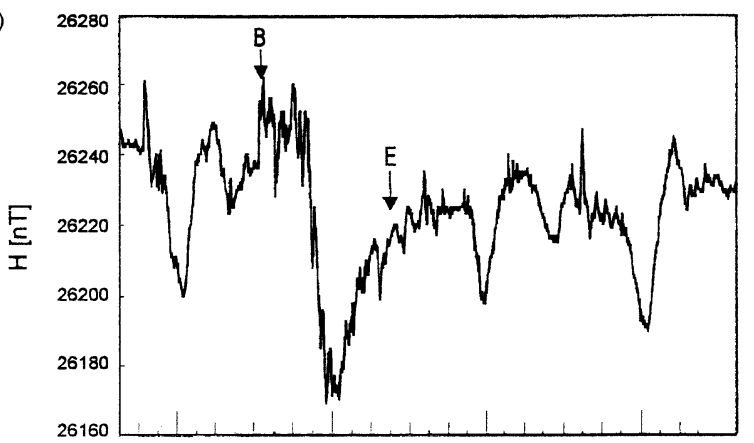

(b)

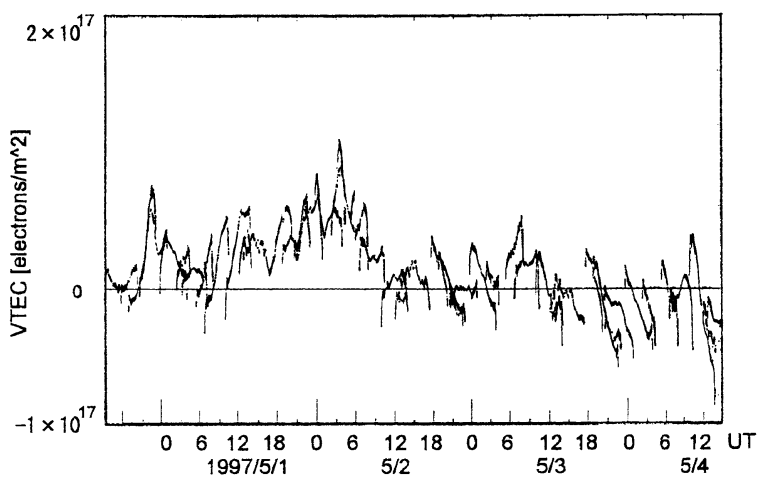

Fig. 3. Variations of (a) magnetic H-component and (b) the perturbation components of TEC associated with magnetic storm of May 1, 1997.

manner that the TEC variation appeared initially as a positive hump, then was followed by a negative level for about two days, and finally returned to the usual-day level as shown in Fig. 2(b). This feature is consistent with the results of earlier investigators (e.g., Nakata, 1966; Mendillo et al., 1969).

A medium-scale storm of May 1-2, 1997 (Fig. 3(a)) also affected the TEC variation during a few consecutive days, which can be identified in (b). The associated TEC variation, however, does not show such a clear pattern as in the case of severe storm.

Of the remaining 6 storm events, no features different from the above examples have been identified. The Feb. 27 and Apr. 16 storm events of the six are categorized into a mediumscale storm, and show a similar variation pattern to the May 1 event. The magnetic storm for Nov. 6-8 resembles the May 15 event in the magnetic field variation. The corresponding TEC variation, however, shows a similar pattern to the Feb. 8 storm shown in Fig. 1(b), i.e., the amplitude decrease in TEC is not so noticeable as that of May 15 event. Each event of Nov. 22, Jan. 6, and Feb. 17 was associated with a severe storm following a small-size magnetic storm as in the case of Feb. $8-10$ storm. The TEC variation pattern is also similar to that of Feb. 8-10 storm.

These results indicate that a seasonal effect exists when we compare the storm event in winter to it in summer, e.g., between Fig. 1(b) and Fig. 2(b), we can see that the amplitude decrease in TEC, which obeys initially positive hump structure, shows a more clear pattern in the May events than in the February ones. This result is consistent with that of earlier investigators (e.g., Titheridge and Buonsanto, 1988).

\section{Discussion and Conclusion}

The ionospheric delay is frequency-dependent, which makes it possible to estimate TEC from the carrier phases and P-code group delays of GPS dual frequency signal. This, in turn, means that the accuracy of ionospheric measurement depends on the determination of the inter-frequency bias between $L_{1}(1575.42 \mathrm{MHz})$ and $L_{2}(1227.60 \mathrm{MHz})$ signals for both the receiver and the satellite. These 2 biases are major factors with respect to the difficulties in the determination of absolute TEC values from GPS observations.

However, considerable evidence indicates that satellite biases can be quite stable, viz., they take 1 TECUPP(one peakto-peak value in TECU), or exhibit very gradual drifts, over periods of several months (Coco et al., 1991; Sardon and Zarraoa, 1997). The receiver biases show a clear diurnal variation(-1 TECUPP) that is probably due to temperature variation (Mannucci et al., 1999). When we consider the inter-frequency biases, we can assume that the TEC includes some common biases for consecutive several days. Thus, our estimation scheme for the perturbation components of storm time GPS-TEC improves the data quality with the accuracy of 1 TECU or less, because the perturbation components of TEC are derived by subtracting the adjacent quiet-time values, i.e., the subtraction almost cancels the inter-frequency biases. As a result of this subtraction, the error sources would be related only to the difference of the propagation paths of GPS signals. From these points of view, our method is useful to investigate the perturbation components of GPS-TEC relative to the determined quiet-time values, of an order of 1 TECU.

Several excellent reviews (e.g., Matuura, 1972; FullerRowell et al., 1997; Buonsanto, 1999) concerning ionospheric storms have been published, in which the effects of 
magnetic storms on TEC are discussed. The ionospheric disturbances during magnetic storms are generally explained in terms of the thermospheric changes in both neutral air winds and composition which result in changes of the rates of production and loss of ionization. At the time of ionospheric storms, negative phases in electron density are often observed in the morning hours, and positive phases in the afternoon as well as evening hours, which result in the local-time variation of the changes in neutral wind and composition at middle latitudes. Rodger et al. (1989) showed the local-time and seasonal variations of the positive and negative phases in electron density as storm effects from their $\mathrm{AC} / \mathrm{DC}$ analysis using a disturbance index $\ln \left(N / N_{0}\right)$, where $N$ means the disturbed-time value of $N_{m} F_{2}$ (maximum electron density corresponding to $f_{o} F_{2}$ ), and $N_{0}$ the quiet-time one. Seasonal DC offset has been found in their analysis, i.e., the index has more positive values in local winter, compared to in summer. This DC offset is thought to be arising from the summer-to-winter thermospheric wind which limits the equatorward penetration of the composition disturbance zone in winter, but expands further equatorward in summer (Buonsanto, 1999). From their AC analysis, the negative phases of electron density are found particularly in the morning sector. The $\mathrm{AC}$ variation of the storm-associated changes in $N_{m} F_{2}$ should be due to the local-time variation of the winds, which are poleward during daylight hours and equatorward at night. Although our analysis does not refer to the same index as his one, similar seasonal characteristics seem to be detected from our observations, i.e., the negative variation phases of TEC are clearly recognized in summer compared to in winter. It is also evident from our observations that the negative TEC phases frequently appear in morning hours. Our speculation on this result is that the ionospheric (and the protonospheric) disturbances of magnetic-storm origin were superposed on the daily evolutionary change of the morning side ionosphere, and then the storm effects on the TEC variations may be often enhanced.

Our results can be summarized as follows: 1) For the typical storm events, the amplitude level of the TEC variation tends to increase during the first $24 \mathrm{hr}$ of magnetic storm, and then decrease below its usual-day level with recovery in one or two days later; 2) During a negative-value phase of the TEC variation, which follows the initial positive hump structure, the perturbation amplitude of TEC shows a remarkable reduction in summer compared to in winter. These features are not inconsistent with the results of earlier investigators such as Nakata (1966), Mendillo et al. (1969), and Titheridge and Buonsanto (1988), which in turn validates our TEC estimation scheme from GPS.

Acknowledgments. The authors wish to thank World Data Center C2 of Kyoto University for providing geomagnetic data.

\section{References}

Buonsanto, M. J., Ionospheric storms-A review, Space Sci. Rev., 88, 563$601,1999$.

Coco, D. S., C. Coker, S. R. Dahlke, and J. R. Clynch, Variability of GPS satellite differential group delay biases, IEEE Trans. Aeros. and Electr. Syst., AES-27, 931-938, 1991.

Fuller-Rowell, T. J., M. V. Codrescu, R. G. Roble, and A. D. Richmond, How does the thermosphere and ionosphere react to a geomagnetic storm?, in Magnetic Storms, edited by B. T. Tsurutani, W. D. Gonzales, Y. Kamide, and J. K. Arballo, pp. 203-225, Geophysical Monograph 98, AGU, 1997.

Jakowski, N., TEC monitoring by using satellite positioning systems, in Modern Ionospheric Science, edited by H. Kohl et al., pp. 371-390, European Geophys. Soc., 1996.

Lu, G., X. Pi, A. D. Richmond, and R. G. Roble, Variations of total electron content during geomagnetic disturbances, Geophys. Res. Lett., 25, 253 256, 1998.

Mannucci, A. J., B. A. Iijima, U. J. Lindqwister, X. Pi, L. Sparks, and B. D. Wilson, 25. GPS and Ionosphere, in Review of Radio Science 1996-1999, edited by W. R. Stone, pp. 625-665, URSI, 1999.

Matuura, N., Theoretical models of ionospheric storms, Space Sci. Rev., 13, 124-189, 1972.

Mendillo, M., M. D. Papagiannis, and J. K. Klobuchar, A seasonal effect in the mid-latitude slab thickness variations during magnetic disturbances, J. Atmos. Terr. Phys., 31(11), 1359-1364, 1969.

Nakata, Y., Variation in ionospheric electron content measured by radio waves from syncom 3, Radio Sci., 1, 1145-1148, 1966.

Rodger, A. S., G. L. Wrenn, and H. Rishbeth, Geomagnetic Storms in the Antarctic F-region. II. Physical interpretation, J. Atmos. Terr. Phys., 51, 851-866, 1989.

Saito, A., S. Fukao, and S. Miyazaki, High resolution mapping of TEC perturbations with GSI GPS network over Japan, Geophys. Res. Lett., 25 , 3079-3082, 1998.

Sardon, E. and N. Zarraoa, Estimation of Total Electron Content using GPS Data-How stable are the differential satellite and receiver instrumental biases, Radio Sci., 32, 1899-1910, 1997.

Titheridge, J. E. and M. J. Buonsanto, A comparison of northern and southern hemisphere TEC storm behaviour, J. Atmos. Terr. Phys., 50, 763-780, 1988

A. Yamamoto (e-mail: yamamoto@msa.ac.jp), Y. Ohta, T. Okuzawa, S. Taguchi, I. Tomizawa, and T. Shibata 